\title{
Physical Activity and Life Quality of Part-Time Students
}

\author{
Liana Plavina ${ }^{1}$ Dr. med.; Helena Karklina ${ }^{2}$ Dr. med. \\ Riga Stradins University, Latvia \\ $\underline{\text { liana.plavina@ rsu.lv }}{ }^{1}$; helena.karlina@ rsu.lv ${ }^{2}$
}

\begin{abstract}
Physical activities are important for everyone in order to keep the physical preparedness and support an adequate level of life quality. Physical activities of young people - students are basis for keeping health capacity, working ability, developing business and carrier, and providing economic and social stability. Sport activities are very popular nowadays. Anyone can choose various sport activities that are suitable and available, that favour physical fitness and increase health status. Physical activities usually are planned during leisure time and weekends. We have provided a questionnaire about physical activities of student groups in period from 2012 till 2016. Studies have indicated the number of smokers, assessed results of questionnaire about physical activity, the body mass, body heights, and anthropometric indices. Results reflected that general physical activity level (in scores) in examined groups - part time students were low for female and moderate for male. Recent research suggests that a significant percentage of students didn't get adequate physical activity. We fixed increased numbers of individuals of both genders who have no any sports activity in the last years. The mean value of body mass index (BMI) for male was above standard. The amount of physical activity of working people has dropped and the resulting poor physical condition is becoming a threat to their working ability, health and well-being. Contemporary life style is connected to full time job that reduces the time dedicated to physical activities. The consequences of physical inactivity are associated to multiple health related problems. Musculoskeletal pathology is one of the most common work-related health problem, as well as an important cause of morbidity for population. It is an inflammatory and degenerative ailment that affects all individuals in working age. The aim of the study is to determine and evaluate the daily physical activities and their general level for the part-time students, give characteristic of anthropometric parameters for part time students.
\end{abstract}

Keywords: physical activity of students, body mass index value, health and fitness of students, adult education.

\section{Introduction}

The level of welfare increases in the European countries as well as in Latvia (Sunite, Kasalis, 2012). The actual problem of modern society is lake of motion (Porozovs, 2010; McLaughlin, Wittert, 2009; Research for universal..., 2013). There is aggravated statistic concerning the level of morbidity and mortality that connect to the decreasing physical activity (Aandstad et al., 2014; Caspersen, Powell, Christtenson, 1985; Dishman, Flemmunig, Kjaer, 2007). Daily physical activity and physical activity is closely associated with physical fitness that characterizes an individual's cardio respiratory status, muscular strength and endurance, as well as velocity and coordination (Heir, Eide, 1996; Kalichman, Kobykiansky, 2005; Nascimento et al., 2008). The individual physical activity level determines the quality of performance of daily duties (Grinberga et al., 2014; Heir, Eide, 1996; Kalichman, Kobykiansky, 2005). Individual physical preparedness is a base for performing duties in the working place and professional carrier successfully. Physical activities are important for everybody to keep physical preparedness and fitness. Everyday's activities of students are connected to physical activities that demand physical preparedness. Physical activities are popular and planned during leisure time as well the weekend (Grinberga et al., 2014; Heir, Eide, 1996; Kalichman, Kobykiansky, 2005). Physical activity, which is closely associated with physical fitness, is an indispensable part of daily routine of everyone. Physical fitness characterizes an individual's cardio respiratory status, muscular strength and endurance, as well as velocity and coordination. It comprises characteristic morphological and functional properties, which ensure that individual is able to do a physical activity. The individual fitness level determines the quality of performance of daily duties. Contemporary life style is connected to full time job that reduces the time for physical activities. The consequences of physical inactivity are associated to multiple health related problems (Grinberga et al., 2014; Kaarma et al., 2007; Latvijas iedzivotaju sportosanas..., 2007).

The aim of the study is to determine the general physical activity level for the part-time students in the Riga Teacher training and education management Academy, as well as to assess their anthropometric characteristics (body mass, height, Body Mass Index). 


\section{Methodology}

Cross-sectional study, carried out from 2012 till 2016, when 108 respondents of both gender in age from 21 till 52 were examined. Participants of the study filled in a structured questionnaire (Vilenskij, Ilinskij, 1987), which included data about individual and organized physical activities on working days, and on weekend, morning exercises, and sports activities for individuals as well as sports activities in groups. Questionnaire responses rendered whether the respondents to work and back go on foot (of moderate intensity load, not less than 20 minutes), go by bicycle (of low or moderate intensity load, if the distance is at least $10 \mathrm{~km}$ ), or use the public transport. Information about eating habits and length of sleep, the days missed from service due to illness, as well as an individual's self-assessment of health was gathered. Respondents also filled in an anonymous questionnaire on smoking and alcohol use. Each answer was allocated a certain number of scores that allow to classified physical activity level of respondents (low, moderate, good and high). As a result of the data statistical analysis and processing, the total level of the respondents' physical activities determined in each years of study group was analysed. Respondents were included into the groups with low, moderate, good, and high physical activity level.

\section{Results and Discussion}

Assessment of daily physical activity patterns for respondents of examined groups included various daily performed physical activities. Assessment of physical activity level, which is characterized by the exercises or daily physical work, allowed grouping respondents into the categories with low, moderate, good, and high physical activity level. Evaluation of the data reveals that the respondents of female group have lower level of physical activity, than respondents of male groups (Figure1). The general level of physical activity in scores for male was from $38 \%$ till $45 \%$ higher than for female in the examined period 2012-2016. The main benefits of physical activity are prevention of diseases, stress management, and improved body building. Recent research suggests that a significant percentage of students do not get an adequate physical activity. Physical activity in the group of female respondents corresponded to the low level from $23.3 \pm 2.8$ (2012) till $25.5 \pm 4.9$ (2016) but physical activity level in the male respondents group is moderate from $32.2 \pm 5.1$ (2012) till $37.2 \pm 6.1$ (2016).

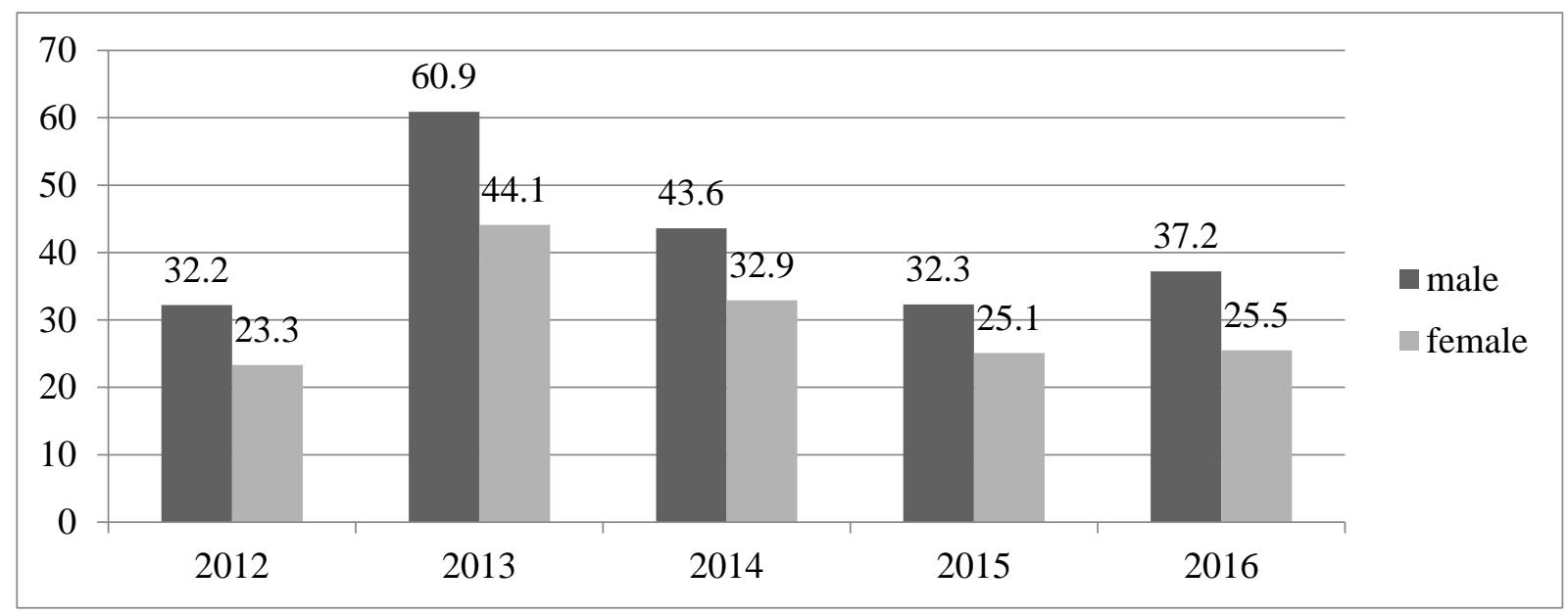

Figure 1. Mean value of physical activity level (in points) for respondents of both genders in examined groups in period 2012-2016.

Levels of physical activity were different for participants in the examined groups. Analysis of general physical activity levels in the female groups reflected that the numbers of respondents with low level physical activity fluctuated from $30 \%$ in 2013 till $83.3 \%$ in 2012, but in the 2016 number of female respondents with low level physical activity composed $55.5 \%$ (Figure 2). About one fourth of all female respondents of examined groups have moderate level of physical activity from $16.6 \%$ in 2012 till $30 \%$ in 2014, but in 2016 they composed $27.8 \%$. The number of female respondents with good and high physical activity level decreased in the last five years from $50 \%$ in 2013 till $11 \%$ in 2016. Analysis of physical activity level in the male - respondents groups shows that good and high level of physical activity were fixed for more than half of respondents in each examined group (Figure 3). The moderate level of physical activity variated from 33.3\% in 2013 till $57.3 \%$ in 2014 and composed $40 \%$ in 2016. 


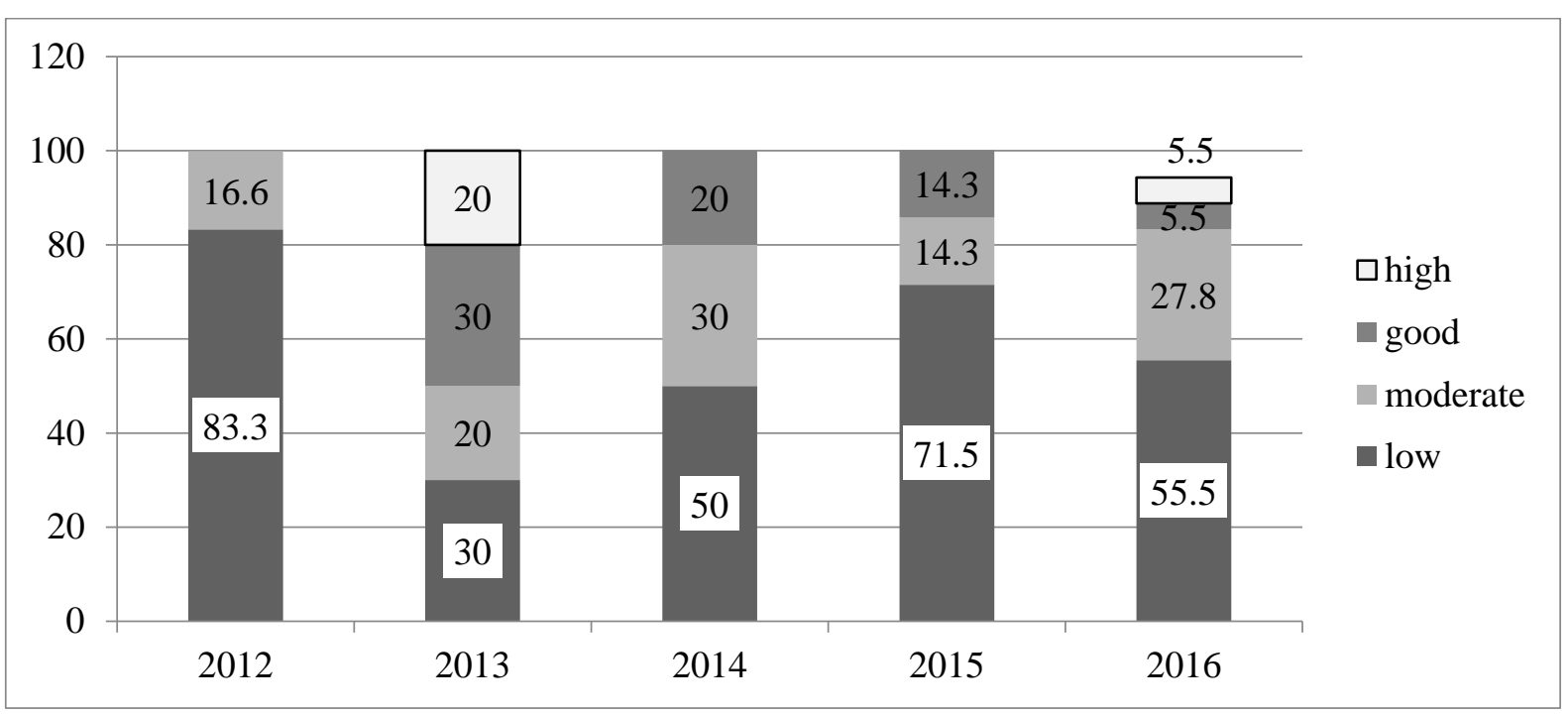

Figure 2. Analysis of physical activity levels (in points) for female in examined groups in period 2012-2016.

Male respondents with low physical activity levels in the lasts years have slowly grown up from $14.3 \%$ in 2014 till $40 \%$ in 2016. But the number of male with good physical activity level gradually decreased from $44.4 \%$ in 2013 till $13.3 \%$ in 2016. The numbers of male respondents with moderate physical activity level fluctuated from $33.3 \%$ till $57.1 \%$.

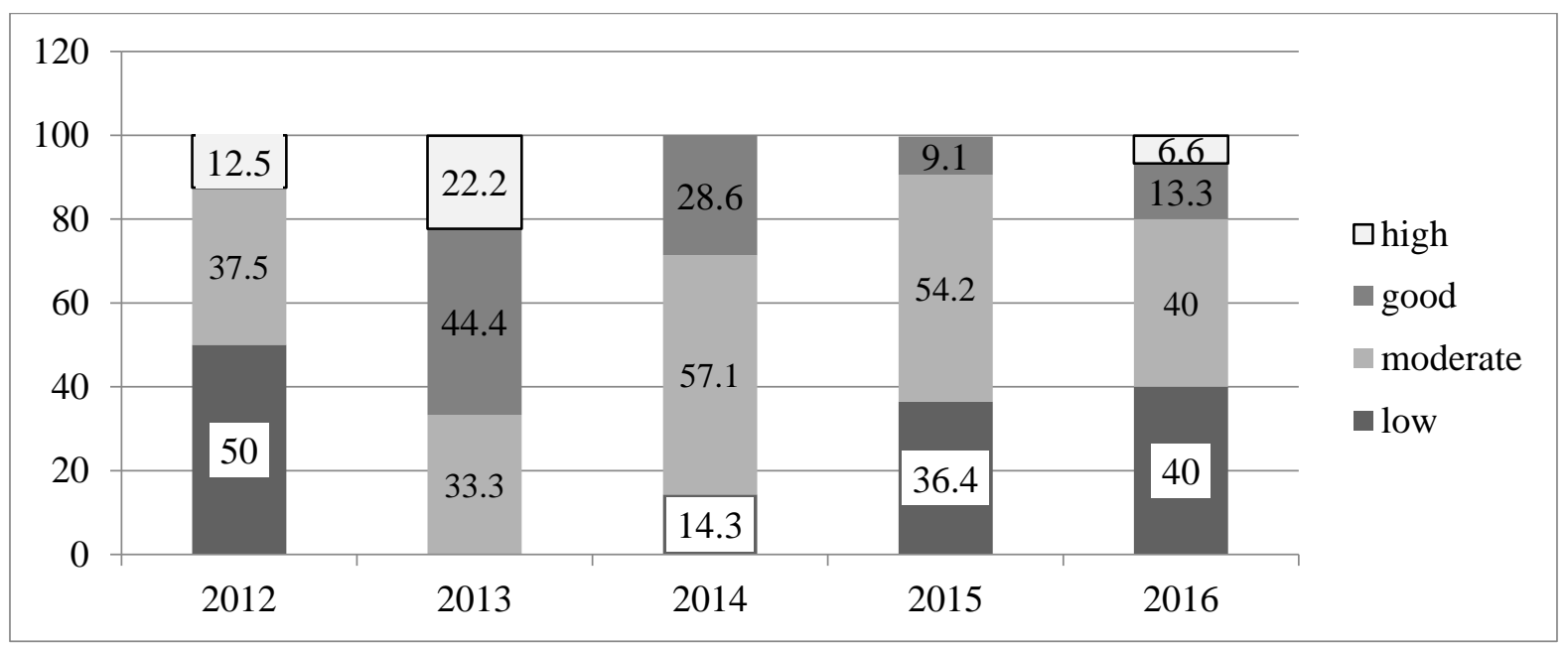

Figure 3. Analysis of physical activity levels (in points) for male in examined groups in period 2012-2016.

Assessment of students' (female) individual and organized sports activities with moderate and high intensity with duration for at least two hours, both outside daily working hours and at weekends, were shown (Figure 4). Number of participants- female in regular sports activities diminished from $40 \%$ in 2014 till $11.1 \%$ in 2016. The numbers of female respondents who didn`t follow any kind of sports activities were from $16.7 \%$ till $28.6 \%$. However about $40 \%-72.2 \%$ female respondents followed non-regular sports activities that is twice more (1.8 times) than males. 


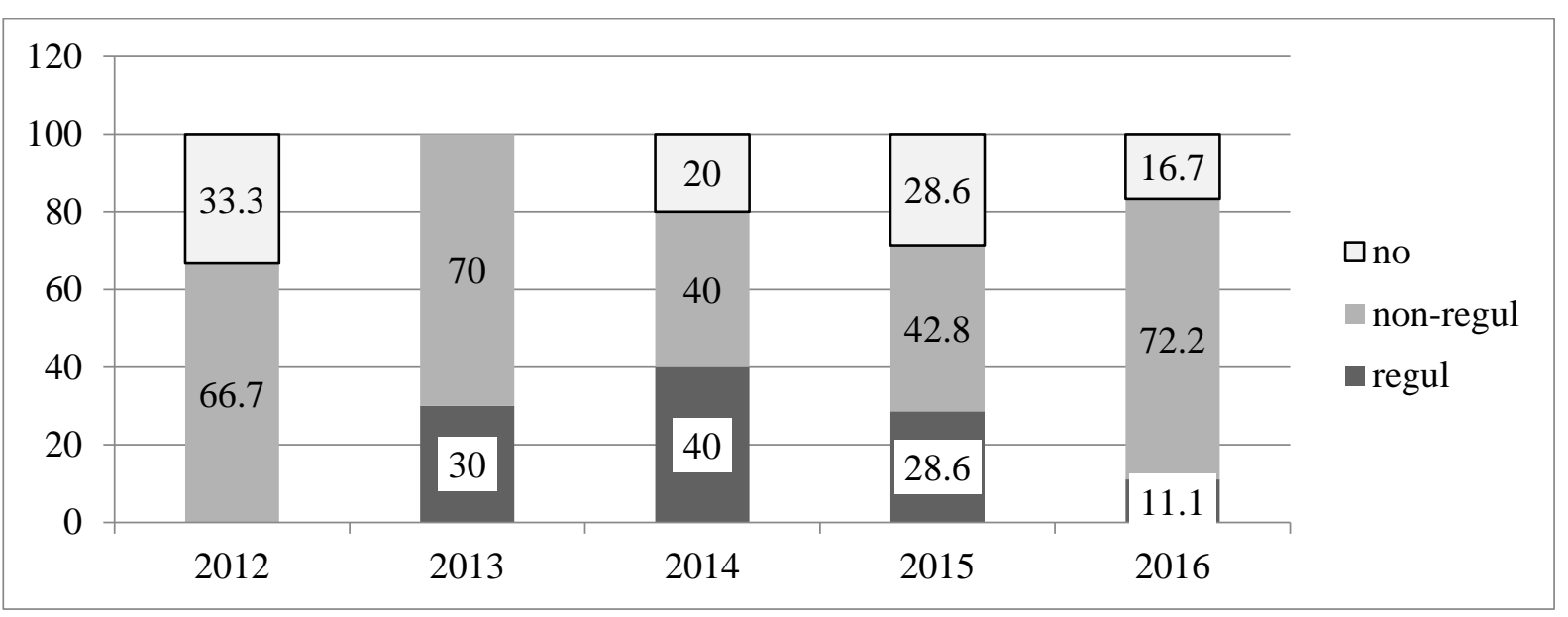

Figure 4. Distribution of female - participants in sports activities during leisure time in examined groups in period 2012-2016.

Situation concerning sports activities during leisure time in male groups is more positive and optimistic (Figure 5). Number of male -respondents who participate in sports activities during leisure time fluctuated from $18.2 \%$ till $55.5 \%$, but in 2016 they composed $33.3 \%$. Numbers of male respondents who had non-regular physical activities were from $37.5 \%$ till $72,7 \%$ in different examined groups (Figure 5). Non-regular sports activities were fixed for $40.0 \%$ for male respondents in 2016. In the examined groups we fixed increasing numbers of individuals (male) who have no sports activity: in the last years from 0 (in 2014) till $26.7 \%$ (in 2016). Numbers of male respondents who have regular physical activities diminished three times form $55.5 \%$ (in 2013) till $33.3 \%$ (in 2016).

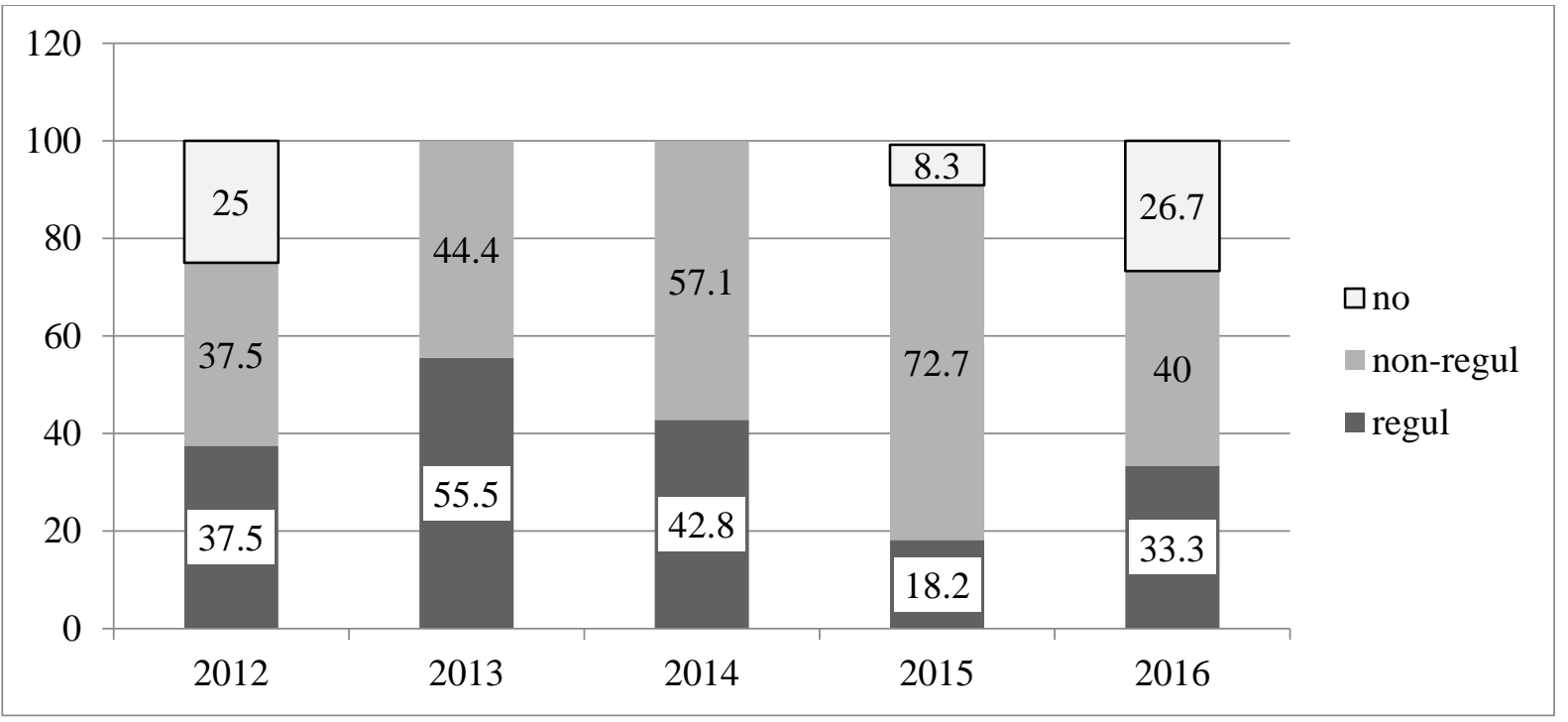

Figure 5. Distribution of male - participants in sports activities during leisure time in examined groups in period 2012-2016.

The $53.3 \%$ of males and $61.3 \%$ of females have regular meals and healthy sleeping arrangement. Analysis of anthropometric characteristics of respondents revealed overweight and adiposity problem. Evaluation of BMI value shows that in the male respondents group the value of body mass index in the standard interval fluctuated from $7.1 \%$ till $36.4 \%$ (Figure 6), however the number of female respondents with value of BMI in the standard interval dominated and composed from $58.3 \%$ till $100 \%$ (Figure 7). In the last years adiposity problems were fixed for $16.7 \%$ male - respondents in 2015 and $28.5 \%$ in 2016. In the female respondent group, we have found overweight problem for $28.6 \%$ in 2016 . 


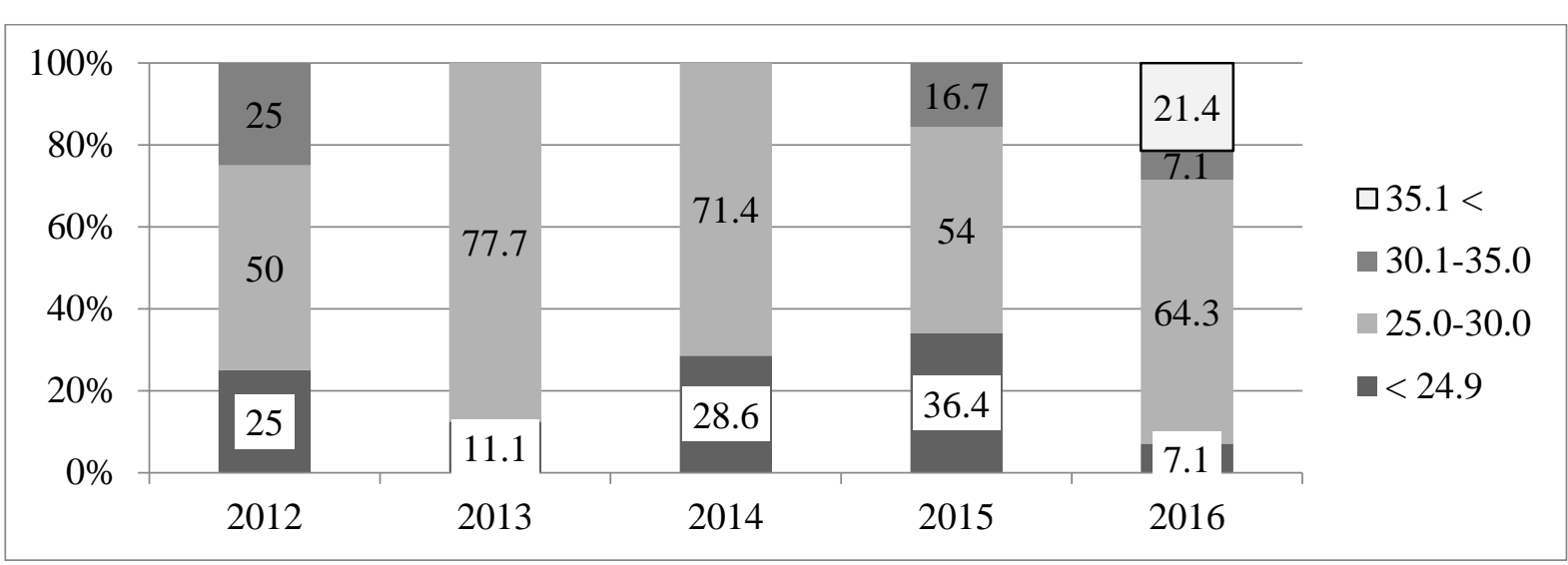

Figure 6. Distribution of male according to the value of BMI groups in period 2012-2016.

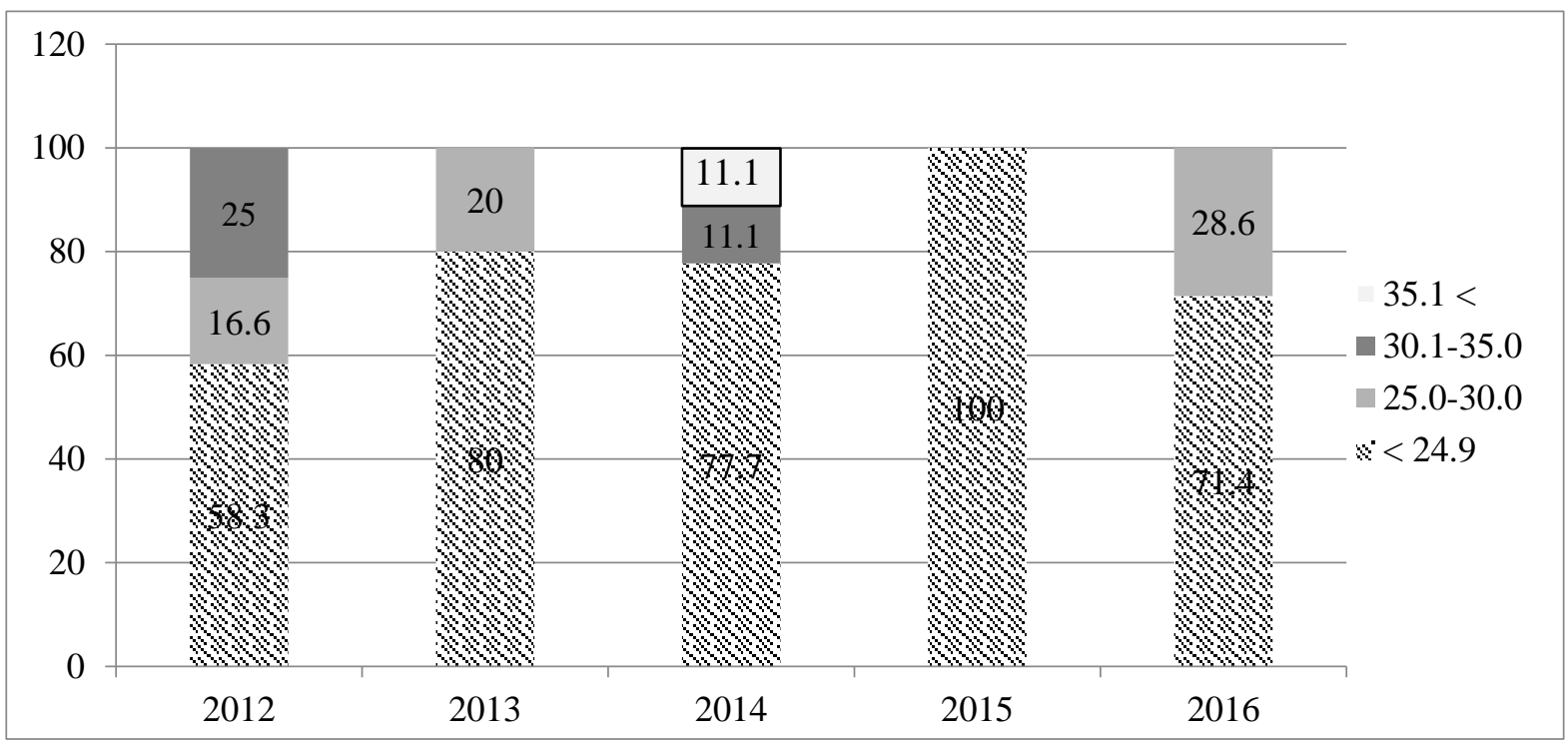

Figure 7. Distribution of female according to the value of BMI groups in period 2012-2016.

We have evaluated mean value of BMI of respondents of both genders in examined groups (Figure 8). The male groups had value of BMI higher than the mean value of BMI in female groups.

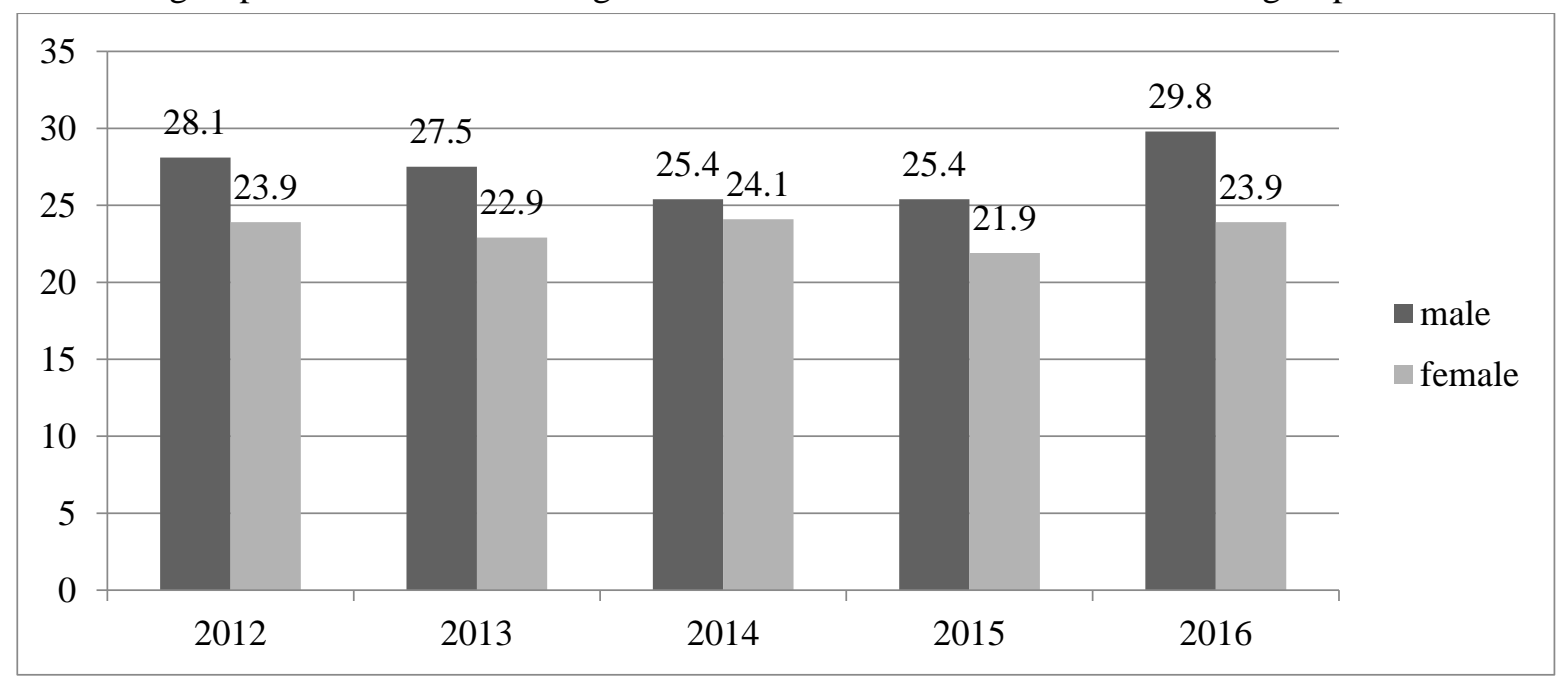

Figure 8. Distribution of mean value of BMI form respondents of both genders in period 2012-2016. 


\section{Conclusions}

- General physical activity level (in scores) in examined groups of students was low for female from 23.3 (in 2012) till $37.2 \pm 6.1$ (in 2016).

- Respondents of examined groups were busy, they involved in daily activities connected to direct job duties as well studies. Recent research suggests that a significant percentage of students didn't get adequate physical activity. Numbers of male respondents who had non-regular physical activities variated from $37.5 \%$ till $72,7 \%$. We fixed increasing numbers of individuals (male) who have no sports activity in the last years from 0 (in 2014) till $26.7 \%$ (in 2016). Regular physical activities are important for 30\% of female respondents in 2013 till $16.6 \%$ in 2016.

- The mean value of BMI for male was above standard and corresponded to the overweight characteristics; they fluctuated from $28.1 \pm 0.9$ (in 2012) till 29.8 1.4 (in 2016). The number of male respondents with adiposity problem (according to WHO standards) increased in the last years. The mean value of body mass index for female corresponded to the WHO standards and changed from $23.9 \pm 0.7$ (in 2012.) till $23.9 \pm 0.9$ (in 2016).

\section{Bibliography}

1. Aandstad A., Hageberg R., Holme I.M., Anderssen S.A. (2014). Anthropometrics, body composition, and aerobic fitness in Norwegian home guard personnel. Journal of Strength and Conditioning Research (JSCR), 28 (11), 3206-3214.

2. Caspersen C.J., Powell K.E., Christtenson G.M. (1985). Physical activity, exercise, and physical fitness: definitions and distinctions for health-related research. Public Health Reports, 100(2), $126-131$.

3. Dishman R., Flemmunig D., Kjaer M. (2007). Why exercise? In J. Kallio, P. Komi, J. Komulainen, J. Avela (Eds.), 12th Congress of the European College of Sport Science (ECSS) in Jyvaskyla, Finland from 11-14 July 2007. Book of Abstracts. Finland: ECSS, 1.

4. Grinberga D., Pudule I., Velika B., Gavare I., Villerusa A. (2014). Latvijas iedzivotaju veselibu ietekmejoso paradumu petijums (Health Behaviour among the Adult Population Survay). Riga: Slimibu profilakses un kontroles centrs. (in Latvian)

5. Heir T., Eide G. (1996). Age, body composition, aerobic fitness and health condition as risk factors for musculoskeletal injuries in conscripts. Scandinavian Journal of Medicine and Science in Sports, $6(4), 222-227$.

6. Kaarma H., Lintsi M., Saluste L., Koskel S., Arend A. (2007). Estonian national norms of height, weight and body mass index for men and women aged 20-70 years. In Papers on Anthropology, XVI. Tartu: Tartu University Press, $139-146$.

7. Kalichman L., Kobykiansky E. (2005). Body composition: variations during the life-span and association with manifestations of aging. In H. Kaarma (Ed.), Papers on Anthropology, XVI. Tartu: Tartu University Press, $147-169$.

8. Latvijas iedzivotaju sportosanas paradumi (Sporting habits of inhabitants of Latvia). (2007). Riga: Tirgus un Sabiedriskas domas petijumu centrs SKDS. (in Latvian).

9. Nascimento R., Martinez E., De Sa Rego Fortes. (2008). Relationship between physical fitness body fat mass and coronary risk factors in military Brazilian males. In J. Cabri, F. Alves, D. Araújo, J. Barreiros, J. Diniz, A. Veloso (Eds.), 13th Annual Congress of the European College of Sport Science (ECSS) in Estoril, Portugal from 9 - 12 July 2008, Book of Abstracts. Portugal: ECSS, 110.

10. McLaughlin R., Wittert G. (2009). The obesity epidemic: implications for recruitment and retention of defence force personnel. Obesity Reviews, 10 (6), 693 - 699.

11. Porozovs J. (2010). Evaluation of Physical activity, lifestyle and health condition of students. In Proceedings of the International Scientific Conference RTTEMA Theory for Practice in the Education of Temporary Society, 5. Riga, Latvia: RTTEMA, $253-259$.

12. Research for universal health coverage: World health report. (2013). Global strategy on diet, physical activity and health. Geneva: World Health Organization.

13. Sunite S., Kasalis E. (2012). Latvian population health quality approximation to the EU level - one of the challenges for persistent EU economic development. European integration studies, 6, 177 - 184.

14. Vilenskij M.Ja., Ilinskij V.I. (1987). Fizicheskaja kultura rabotnikov umstvennogo truda (Physical activity of intellectual workers). Moskva: Znanie. (in Russian). 